RELATO DE CASOS

\title{
Pênfigo Vegetante: Relato de Caso
}

\author{
Pemphigus Vegetans: Case Report
}

\author{
JUVENAL DA ROCHA TORRES NETO ${ }^{1}$, RODRIGO R. SANTIAGO ${ }^{2}$, ANACAROLINALISBOAPRUDENTE $^{3}$, DAN \\ RODRIGUES MARIANO ${ }^{4}$, JÚLIO AUGUSTO DO PRADO TORRES ${ }^{5}$, FELIPEAUGUSTO DO PRADOTORRES $^{6}$, RAQUEL $^{2}$ \\ MATOS DE SANTANA ${ }^{7}$, FERNANDA MENDONÇARAMOS $^{8}$, MÔNICA DE ARAÚJO $^{9}$ \\ ${ }^{1}$ Professor, doutor e chefe do Serviço de Coloproctologia da UFS, ${ }^{2}$ Residente de coloproctologia da UFS, ${ }^{3}$ Residente de \\ Coloproctologia da UFS, ${ }^{4}$ Residente de Coloproctologia da UFS, ${ }^{5,6,7,8}$ Acadêmicos de Medicina da UFS, ${ }^{9}$ Médica \\ Patologista.
}

TORRES NETO JR; SANTIAGO RR; PRUDENTE ACL; MARIANO DR; TORRES JAP; TORRES FAP; SANTANA RM; RAMOS FM; ARAÚJO M. Pênfigo Vegetante: Relato de Caso. Rev bras Coloproct, 2010;30(2): 210-214.

RESUMO: Pênfigo é uma doença bolhosa auto-imune. É uma doença rara, mas potencialmente fatal. Existem quatro variantes clínicas e patológicas: o pênfigo vulgar (PV), o pênfigo vegetante (PVg), o pênfigo foliáceo (PF), o pênfigo eritematoso. Ao exame histo-patológico o achado comum a todos os tipos de pênfigo é a acantólise. Relatamos o caso de um paciente de 43 anos com lesões ano-perineais cujo diagnóstico final foi de pênfigo vegetante, associado à HPV (Papiloma Vírus Humano), com revisão da literatura.

Descritores: Pênfigo, doença bolhosa, doença auto-imune, vegetante.

\section{INTRODUÇÃO}

Pênfigo é uma doença bolhosa auto-imune. É uma doença rara (com uma incidência de $0,5-3,2$ pessoas por ano no mundo), que pode ser fatal. A maioria dos indivíduos que desenvolve a patologia está entre a quarta e sexta décadas de vida, embora o acometimento juvenil (mais raro) já tenha sido relatado. Afeta todas as raças, com maior incidência nos judeus e nos japoneses ${ }^{(1)}$. Não existe diferença na incidência em ambos os gêneros ${ }^{(2,3)}$.

Existem quatro variantes clínicas e patológicas: o pênfigo vulgar (PV), o pênfigo vegetante (PVg), o pênfigo foliáceo (PF), o pênfigo eritematoso.

Ao exame histo-patológico o achado comum a todos os tipos de pênfigo é a acantólise. Esse termo implica dissolução, ou lise dos sítios de adesão celular dentro da superfície epitelial escamosa, com conseqüente formação de bolhas. As células que se des- prendem das outras células epiteliais (células acantolíticas) perdem sua forma poligonal e tornam-se arredondadas (Figura 1).

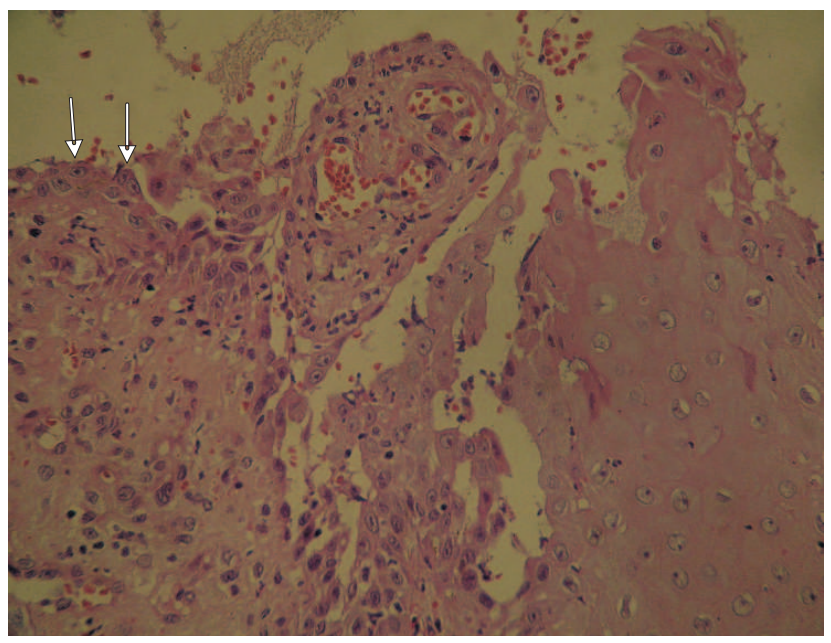

Figura 1 - Setas apontando células acantolíticas.

Trabalho realizado no Hospital Universitário da Universidade Federal de Sergipe (HU-UFS) - Aracaju - SE - Brasil.

Recebido em 19/06/2009

Aceito para publicação em 22/06/2009 
O soro do paciente com pênfigo contém anticorpos IgG para a substância do cimento intercelular da pele e das membranas mucosas. Isso é a base para o diagnóstico por imunofluorescência (RIF) direta e indireta, da pele e do soro. Apesar da diferenças clínicas e histológicas, o PV e o PVg não se diferenciam por RIF ${ }^{(4)}$.

\section{DESCRIÇÃO DO CASO}

M.C.S, 43 anos, gênero masculino.

Paciente relatou que há dois anos começou a apresentar aftas grandes e dolorosas frequientemente, na boca inteira. O médico que o acompanhava solicitou sorologia para HIV cujo resultado foi negativo (o teste para HIV foi repetido outras duas vezes, por diferentes profissionais, com intervalos de no mínimo seis meses). Relata ter usado medicação (não lembra qual) não obtendo, no entanto, melhora. Procurou então um dermatologista que receitou dapsona + dipropionato de betametasona, obtendo uma pequena melhora. Posteriormente procurou outro profissional, um alergista, que julgou que as lesões eram provavelmente bacterianas, receitando antibiótico, mas não conseguindo melhora do quadro.

Aproximadamente oito meses após o início das primeiras lesões, paciente relata piora intensa do quadro inicial (com considerável perda de peso: $7 \mathrm{Kg}$ ), com aparecimento de outras lesões pelo corpo e algumas delas sangrantes. Procurou então outro dermatologista que prescreveu prednisona e antibióticos, obtendo melhora das lesões bucais e remissão das lesões no restante do corpo, havendo, no entanto, recidiva das mesmas.

Posteriormente procurou o serviço de coloproctologia em virtude de presença de lesões verrucóides perianais e de canal anal. Foi submetido à excisão das lesões e cauterização. $\mathrm{O}$ anatomopatológico foi sugestivo de HPV (Papiloma vírus humano). No pós-operatório evoluiu com aparecimento de lesões vegetantes, irregulares de crescimento rápido, exudativas (Figura 2), o que nos fez suspeitar de doença de Crohn ou Doença de Behçet. O teste de punção de antebraço para Behçet foi negativo. Foi também aventada a possibilidade de infecção pós-operatória, mas não houve melhora com uso de antibióticos.

Realizamos biópsia e anatomopatológico das lesões cuja microscopia evidenciou fragmentos de pele exibindo acantose, discreta papilomatose e alteração

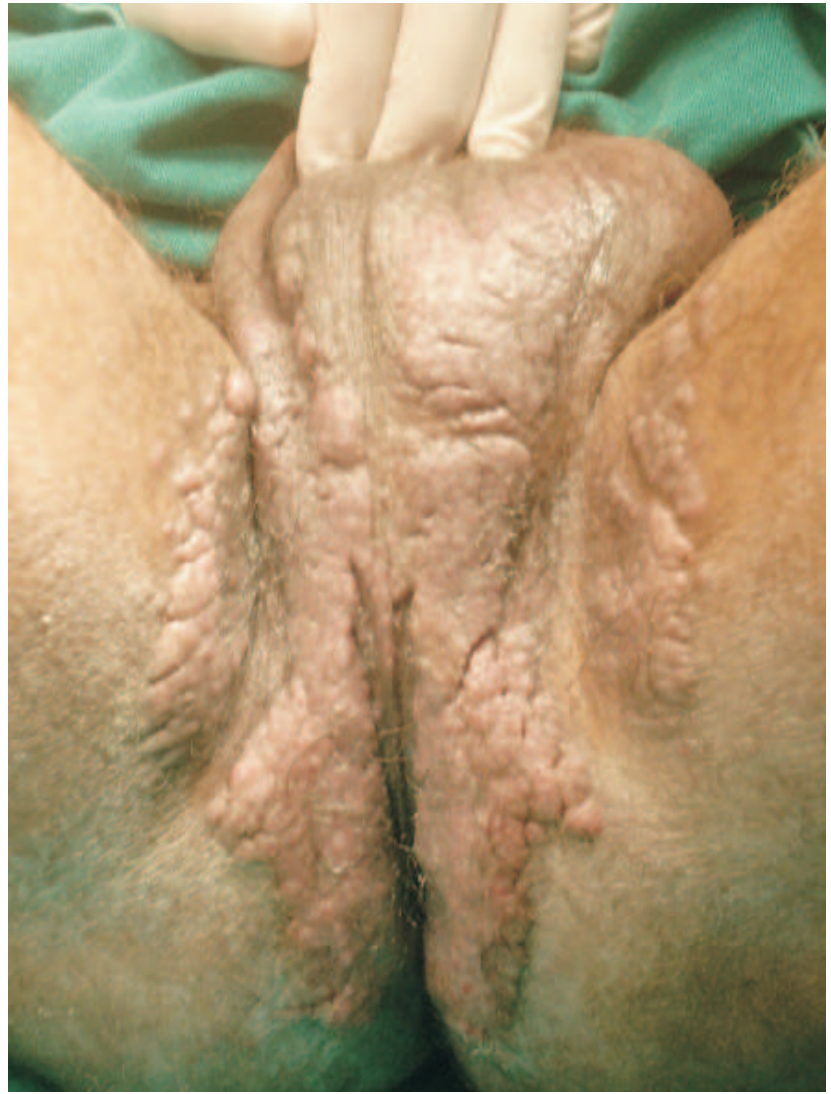

Figura 2 - Lesão vegetante e exudativa em região perianal $e$ perineal.

acantolítica supra basal discreta, com formação de fendas e "vilos". Presença de acentuado edema em derme papilar, acompanhado de infiltrado inflamatório misto denso, rico em eosinófilos, neutrófilos, linfócitos e esparsos plasmócitos. Presença de exocitose de eosinófilos, além de formação de microabscesso eosinofílico em base de crista epidérmica. Nota-se ainda, presença de paraceratose, hipergranulose focal e ocasionais células com núcleos aumentados, irregulares e hipercromáticos, circundados por halo claro na superfície epidérmica.

A conclusão foi de lesão acantolítica supra basal, com acantose, exocitose eosinofílica e micro abscesso de eosinófilos (figura 3 ).

O patologista reviu as lâminas das lesões orais com as mesmas características histopatológicas, cujo conjunto sugeriu pênfigo vegetante.

Foi iniciado o tratamento com prednisona 60 $\mathrm{mg} / \mathrm{dia}(1 \mathrm{mg} / \mathrm{Kg} / \mathrm{dia})$. Houve remissão progressiva das lesões anais e perineais (Figura 4); no momento com $20 \mathrm{mg} /$ dia de prednisona, assintomático (Figura 5). Não 


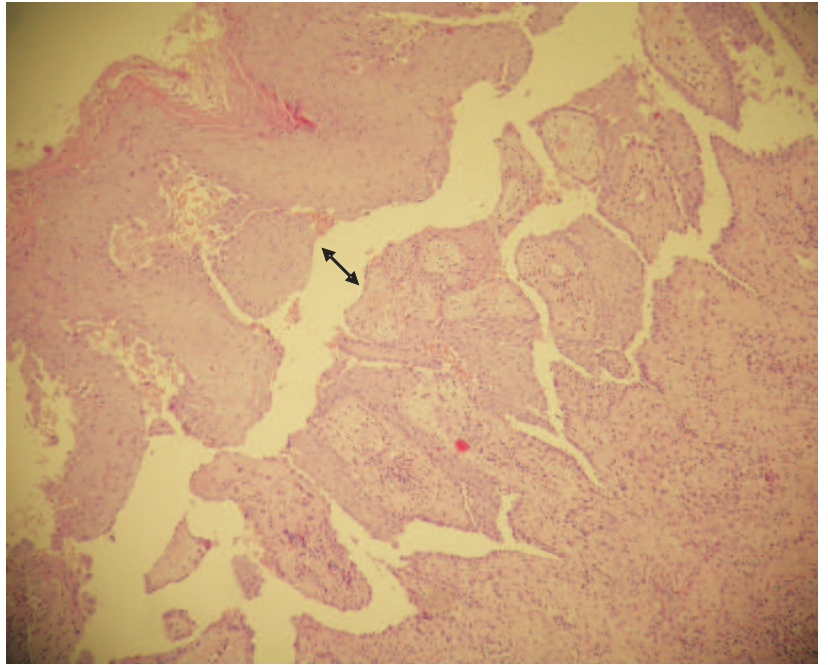

Figura 3 - Dupla seta indicando local da acantólise supra basal.

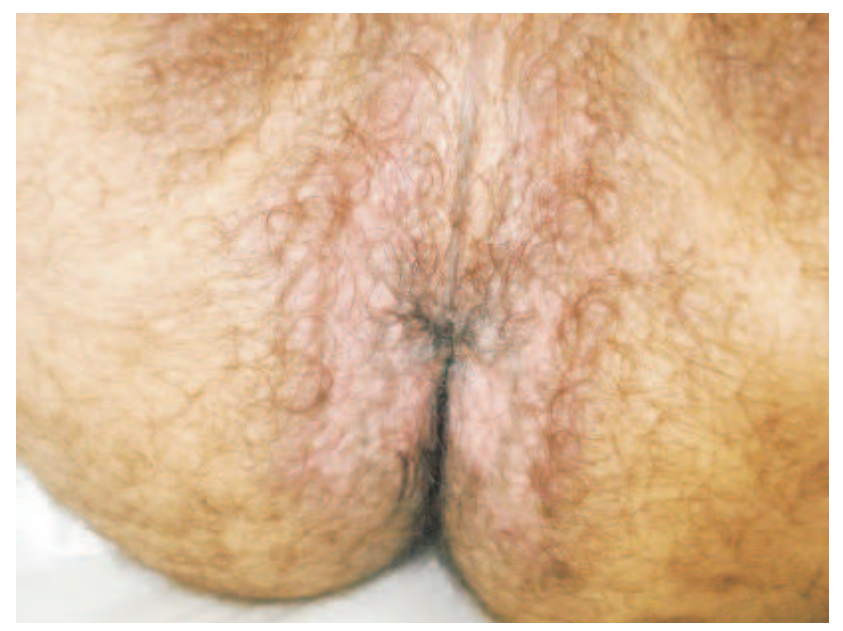

Figura 4 - Remissão das lesões após tratamento com prednisona.

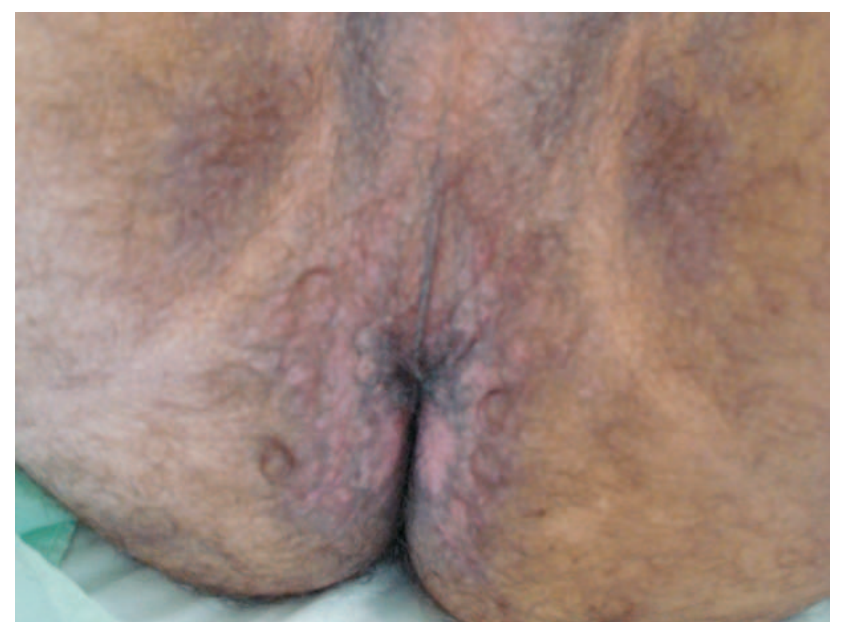

Figura 5 - Remissão total das lesões. há sinais de recidiva das lesões verrucóides sugestivas de HPV.

Atualmente o paciente tem acompanhamento psicoterápico; as lesões da boca e do restante do corpo estabilizaram, permitindo a ingestão normal de alimento e normalização ponderal.

\section{DISCUSSÃO}

O pênfigo é uma doença auto-imune que tem sua etiopatogenia relacionada com a produção de autoAc (auto anticorpo) contra proteínas específicas localizadas nas junções das células epiteliais, rompendo a adesão das mesmas (o que leva à acantólise, com conseqüente formação das bolhas). Estes auto-Ac são principalmente IgG (sobretudo IgG1, IgG4), com muito menor participação de IgM. Também se pode detectar o depósito de complemento, especialmente a fração C3 ${ }^{(5)}$. O achado desses auto-Ac são a base da imunofluorescência. Os títulos de auto-Ac refletem a atividade da doença e são úteis para avaliar a evolução e o tratamento da doença. A recuperação se correlaciona com uma diminuição dos títulos de IgG4, permanecendo os títulos de IgG1 inalterados, demonstrando o importante papel patogênico da IgG4 ${ }^{(5)}$.

O pênfigo já foi descrito associado a outras doenças auto-imunes como artrite reumatóide, miastenia grave, lúpus eritematoso e anemia perniciosa, o que demonstra a possível predisposição genética a doenças auto-imunes concomitantes. No entanto parece que os fatores genéticos não são exclusivos na etiologia da enfermidade como fazem suspeitar a detecção de auto-Ac em pacientes sadios, ou a baixa taxa de concordância entre gêmeos monozigóticos. De alguma maneira existe também a participação de fatores ambientais e foram descritos fármacos, vírus, alimentos, queimaduras, exposição-UV relacionando-se com o pênfigo ${ }^{(5)}$. Discutimos a possível relação entre o stress cirúrgico após excisão de lesão por HPV com o início do aparecimento das lesões vegetantes perianais.

Existem quatro variantes clínicas e patológicas: pênfigo vulgar, pênfigo vegetante, pênfigo foliáceo, pênfigo eritematoso. $O$ pênfigo vulgar (PV) é o tipo mais comum (correspondendo a $80 \%$ dos casos); ocorre sob a forma de vesículas e bolhas que posteriormente se rompem; ele acomete a mucosa e a pele, especialmente o couro cabeludo, face, axila, virilha, tronco e pontos de pressão. $\mathrm{O}$ pênfigo vegetante $(\mathrm{PVg})$, se apresenta não como bolhas, mas como placas 
vegetantes grandes, úmidas, verrucosas, salpicadas com pústulas, nas virilhas, axilas e superfícies flexurais. $\mathrm{O}$ pênfigo foliáceo (PF) é a variável mais benigna, que ocorre de forma epidêmica na América do Sul; nele as membranas mucosas raramente são acometidas. O pênfigo eritematoso é considerado uma variável do PF, que envolve seletivamente a área malar da face (de modo semelhante ao lúpus eritematoso).

Ao exame histo-patológico o achado comum a todos os tipos de pênfigo é a acantólise. Esse termo implica dissolução, ou lise dos sítios de adesão celular dentro da superfície epitelial escamosa. As células acantóticas que não se encontram mais ligadas a outras células epiteliais perdem sua forma poligonal e tornam-se caracteristicamente redondas. No PV e no PVg a acantólise envolve seletivamente a camada de células imediatamente acima da camada basal (no PVg há também associado, uma considerável hiperplasia epidérmica). Além disso, o PV quando comparado ao PVg, quase não apresenta papilomatose, e, a acantólise se apresenta de modo muito mais discreto que no PVg (fatos estes que levaram o patologista responsável ao diagnóstico final de PVg). No PF a acantólise acomete células da camada mais superficial da epiderme. Uma infiltração dérmica superficial variável por linfócitos, histiócitos e eosinófilos acompanha todas as formas de pênfigo.

O PVg foi descrito por Neumann em 1876 e se considera como uma variedade rara do $\mathrm{PV}$ (correspondendo a $5 \%$ dos casos) ${ }^{(6)}$. Crê-se que esteja relacionado com um aumento da agressividade do PV (7).

O PVg começa com um pênfigo vulgar com bolhas na pele e nas mucosas que, depois começam a vegetar. Essas considerações têm relevância no caso relatado, pois as lesões do paciente eram, inicialmente, bolhas na mucosa oral, posteriormente espalhando-se para pele de outras regiões sob forma de placas vegetantes.

Este pênfigo tem características próprias, não só do ponto de vista clínico e histológico, senão tam- bém de prognóstico e tratamento. O diagnóstico é feito com base na apresentação clínica, no exame histopatológico e na imunofluorescência das lesões, esta confirmando a suspeita microscópica de pênfigo. Não foi, no entanto, feita no nosso caso já que o paciente já respondia ao tratamento. É uma doença rara, com uma incidência de $0,5-3,2$ pessoas por ano no mundo, que pode ser fatal. A maioria dos indivíduos que desenvolvem a patologia está entre a quarta e sexta décadas de vida, coincidindo com o nosso relato de caso (43anos), embora o acometimento juvenil, mais raro, já tenha sido relatado.

O diagnóstico diferencial do PVg deve ser feito com: Condilomas acuminados, Doença de Crohn, Doença de Behçet, Condilomata Lata, Candidose Mucocutânea Crônica, Impetigo contagioso de pequenas vesículas, Síndrome de Lyell, Penfigóide Bolhoso, Pênfigo crônico familiar benigno, Disqueratose folicular, Bromoderma Tuberosum e Iododerma Tuberosum.

$\mathrm{O}$ tratamento do $\mathrm{PV} / \mathrm{PVg}$ frequientemente envolve o uso de medicamentos imunossupressores, e os esteróides têm sido a droga de escolha no manejo clínico. O prognóstico de pacientes com pênfigo melhorou drasticamente com a introdução do uso de corticóides. $\mathrm{O}$ tratamento inicial do $\mathrm{PV} / \mathrm{PVg}$ requer o uso de corticóides sistêmicos, tal como prednisona. Outras terapias podem ser utilizadas com agentes imunossupressores como: azatioprina, ciclofosfamida, metotrexato, ciclosporina. Novos agentes como o micofenolato mofetil e o tacrolimus em monoterapia ou terapia combinada com baixas doses de corticóides também podem ser uma escolha ${ }^{(8,9,10)}$.

$\mathrm{O}$ esquema utilizado pelo paciente foi de prednisona $1 \mathrm{mg} / \mathrm{kg} /$ dia como dose inicial, e redução gradativa da dose após o controle da doença com a remissão das lesões orais e cutâneas, devendo mantêlo com terapia imunossupressora com azatioprina a 2,5 $\mathrm{mg} / \mathrm{Kg} /$ dia.

Chamamos atenção para a possibilidade de diagnóstico diferencial de lesões cutâneas ano-perineais que podem confundir o coloproctologista.

\footnotetext{
ABSTRACT: Pemphigus is a bollous auto-immune disease. It's a rare disease, but potentially fatal. There are four clinical and pathological variants: pemphigus vulgaris, pemphigus vegetans, pemphigus foliaceus and pemphigus erythematosus. Through the histopathological exam, the common characteristic to all types of pemphigus is the acantholyse. It's reported a case of a pacient of 43 years old with anal and perineal blesses witch final diagnosis was pemphigus vegetans, associated to HPV (Human Papilloma Virus), with literature review.
}

Key words: Pemphigus, bollous disease, auto-imune disease, vegetant. 


\section{REFERÊNCIAS}

1. Bagán JV Enfermedades ampollares de la cavidad oral (I): pénfigos. In: Bagán JV, Ceballos A, Bermejo A, Aguirre JM, Peñarrocha $\mathrm{M}$, editors. Medicina Oral. Barcelona: Masson; 1995. p.220-6.

2. Scully et al - Pemphigus vulgaris: the manifestations and long term management of 55 patients with oral lesions. British J Dermatol 1999; 140: p 84-92

3. Robinson JC, Lozada-Nur F - Oral pemphigus vulgaris. A review of the literature and a report on the management of 12 cases. Oral Med Oral Pathol Oral Radiol Endod 1997; 84: p 349-55

4. Parodi A, Stanley J, Ciaccio M, Rebora A - Epidermal antigens in pemphigus vegetans. Report of a case. Br J Dermatol 1988; 119: p 799-802

5. Martell P, Joly P - Pemphigus: autoimmune diseases of keratinocyte's adhesion molecules. Clinics in Dermatology 2001; 19: p 662-74

6. Downie J, Dicostanzo D, Cohen S - Pemphigus vegetansNeumann variant associated with intranasal heroin abuse. J Am Acad Dermatol 1998; 39: p 872-875
7. James WD, Arnold HL, Odom RB Chronic blistering or pustular dermatoses. In: Andrew's. Diseases of the skin: Clinical Dermatology. 8th ed. Philadelphia: WB Saunders; 1990. p. 539.

8. Stanley JR - Therapy of pemphigus vulgaris. Arch Dermatol 1999; 135: p 76-8

9. Mimouni D, Anhalt GJ - Pemphigus. Dermatologic therapy 2002; 15: p 362-8.

10. Mimouni D et al - Differences and similarities among expert opinions on the diagnosis and treatment of pemphigus vulgaris. J Am Acad Dermatol 2003; 49: p 1059-62.

\section{Endereço para correspondência:}

JUVENAL DA ROCHA TORRES NETO

Rua Ananias Azevedo No. 100, apto. 902

Bairro Praia 13 de Julho

Aracaju-SE

E-mail: jtorres@infonet.com.br

Tel.(fax).: (79) 32144830 